\title{
Eryphus Perty, 1832 e Tacyba, um novo gênero de Heteropsini (Coleoptera, Cerambycidae, Cerambycinae).
}

\author{
Dilma Solange Napp ${ }^{2,4}$ \\ Ubirajara R. Martins ${ }^{3,4}$
}

\begin{abstract}
Eryphus Perty, 1832 and Tacyba, a new genus of Heteropsini (Coleoptera, Cerambycidae). Some species, up to now, included in Callideriphus Blanchard, 1851 are rearranged in: a) those congeneric with Callideriphus grossipes Blanchard, 1851 and b) not congeneric. The first set of species will be treated in a future paper; the second one, on the other hand, is subdivided into Eryphus Perty, 1832 and Tacyba gen. nov. Eryphus Perty, 1832 (type species: Eryphus bipunctatus Perty, 1832), a valid genus, is redescribed and a key for the species is also provided. The following species are transferred to Eryphus: E. bivittatus (Melzer, 1934) comb. nov., E. carinatus (Zajciw, 1970) comb. nov., E. flavicollis (Fisher, 1938) comb. nov., E. laetus (Blanchard, 1851) comb. nov., E. marginatus (Zajciw, 1970) comb. nov., E. picticollis (Gounelle, 1911) comb. nov., E. transversalis (Fairmaire \& Germain, 1864) comb. nov. New synonym proposed: Eryphus bipunctatus Perty, 1832 = Callideriphus atricollis Melzer, 1931. New taxa described: Eryphus tacuarembo sp. nov. (Uruguay, Tacuarembó), E. carioca sp. nov. (Brazil, Rio de Janeiro); Tacyba gen. nov. (type species: Callideriphus maculatus Cerda, 1988). Species transferred to Tacyba and synonyms: T. maculata (Cerda, 1988) comb. nov., T. tenuis (Blanchard, 1851) comb. nov. = Callideriphus testaceicornis Fairmaire \& Germain, 1859 syn. nov. = Callideriphus clathratus Fairmaire \& Germain, 1860 syn. nov. = Callideriphus niger Philippi \& Philippi, 1864 syn. nov. Callideriphus flavicollis m. quadripunctatus Fuchs, 1961 and Callideriphus flavicollis m. reductus Fuchs, 1961, both names of infrasubspecific category (not available under the rules of ICZN), are herein treated as intraspecific variation of Eryphus picticollis (Gounelle, 1911) which occur in southern Brazil and Argentina.
\end{abstract}

Keywords. Callideriphus; Eryphus; Heteropsini; Tacyba; taxonomy.

\section{INTRODUÇÃO}

MonNÉ (1994) arrolou no gênero Callideriphus Blanchard, 1851, 19 espécies. Callideriphus bicolor (Olivier, 1790) foi transferida para Chrysoprasis A.-Serville, 1834 (NAPP \& MARTINS 1995) e Callideriphus collaris Philippi \& Philippi, 1864, para Unabiara (NAPP \& MARTINS 2002).

As espécies que julgamos congenéricas com Callideriphus grossipes Blanchard, 1851 (C. flavipennis Melzer, 1934; C. rubricollis Melzer, 1934 e C. signaticollis Melzer, 1934) serão examinadas numa próxima contribuição. Nestas espécies o pronoto apresenta rugas longitudinais em toda a superfície, as cavidades coxais anteriores são transversas e angulosas aos lados, a fronte é quase vertical, os metafêmures apresentam clavas abruptas e achatadas, os lobos oculares inferiores são mais curtos do que as genas e os artículos apicais dos palpos são cilíndricos.

Para as espécies que julgamos não-congenéricas com $C$. grossipes, restabelecemos Eryphus Perty, 1832, nome válido, porém nunca utilizado e estabelecemos Tacyba gen. nov. As espécies de ambos os gêneros têm pronoto pontuado ou microesculturado e opaco, as cavidades coxais anteriores arredondadas ligeiramente angulosas aos lados, fronte oblíqua, metafêmures gradualmente clavados, com clava cilíndrica, lobos oculares inferiores mais longos do que as genas e ocupam quase toda a região lateral da cabeça e artículos apicais dos palpos expandidos para o ápice.

O nome Eryphus foi utilizado por PERTY (1832: 91) para $E$. bipunctatus, espécie descrita e ilustrada, o que o torna disponível. Eryphus não é homônimo de Eriphus AudinetServille, 1834, pertencente à tribo Trachyderini (ICZN 1999: 58, art. 56.2).

Siglas mencionadas no texto referem-se às seguintes instituições: Departamento de Zoologia, Universidade Federal do Paraná, Curitiba (DZUP); Fundación y Instituto Miguel Lillo, Universidad Nacional de Tucumán, Tucumán (IMLA); Museo Argentino de Ciencias Naturales, Buenos Aires (MACN); Museo Nacional de Historia Natural, Santiago (MNNC); Museum and Art Gallery, Doncaster (MAGD); Muséum National d'Histoire Naturelle, Paris (MNHN); Museu de Ciências

1. Contribuição n 1304 do Departamento de Zoologia, Universidade Federal do Paraná.

2. Departamento de Zoologia, Universidade Federal do Paraná. Caixa Postal 19020, 81531-990 Curitiba - PR, Brasil.

3. Museu de Zoologia, Universidade de São Paulo. Caixa Postal 42594, 04299-970 São Paulo - SP, Brasil.

4. Pesquisador do CNPq. 
Naturais, Fundação Zoobotânica do Rio Grande do Sul, Porto Alegre (MCNZ); Museu Nacional, Universidade Federal do Rio de Janeiro, Rio de Janeiro (MNRJ); Museu de Zoologia, Universidade de São Paulo, São Paulo (MZSP).

Considerando a publicação de catálogo (MonNÉ 1993, 1994) que arrola as citações pertinentes de cada táxon, apenas as referências das descrições originais e desse catálogo são citadas sob cada táxon. Quando necessário, outras são acrescidas.

\section{Eryphus Perty, 1832}

Eryphus Perty, 1832: 91.

Espécie-tipo: Eryphus bipunctatus Perty, 1832 por monotipia.

Corpo e pernas com pilosidade amarelo-esbranquiçada, longa e ereta. Fronte transversa, plana e oblíqua. Genas reduzidas. Olhos finamente facetados, emarginados; lobos oculares inferiores bem desenvolvidos, proeminentes, ocupam toda a região lateral da cabeça. Mandíbulas delgadas, de secção triangular, não angulosas na face lateral externa, aguçadas no ápice. Artículos apicais dos palpos maxilares e labiais curtos e dilatados para o ápice. Antenas com 11 artículos, filiformes, desarmadas, sem sulcos ou carenas; nos machos, atingem ou ultrapassam os ápices dos élitros em até três artículos, nas fêmeas, desde mais curtas até tão longas quanto o corpo. Escapo cilíndrico um pouco engrossado, mais curto que o antenômero III, este mais curto que V. Antenômero IV subigual ou mais curto que o III e o V; V o mais longo; VII-X subiguais, filiformes ou um pouco expandidos no ápice externo.

Protórax mais largo que longo, arredondado aos lados. Pronoto sem tubérculos. Prosterno com pontuação sexual. Cavidades coxais anteriores ligeiramente angulosas aos lados e abertas atrás. Processo prosternal estreito entre as procoxas, levemente expandido no ápice. Processo mesosternal tão largo ou pouco mais estreito que uma mesocoxa, os lados subparalelos e sem projeções articulares, o ápice com entalhe para encaixe do metasterno. Cavidades coxais médias fechadas aos lados. Pro- e mesocoxas arredondadas, não projetadas.

Élitros mais largos que a base do protórax, aplanados no dorso, os lados subparalelos. Epipelura sinuosa, mais estreita e em declive após o úmero.

Fêmures pouco e gradualmente clavados. Metafêmures, nos machos, atingem ou não os ápices dos élitros; nas fêmeas, mais curtos. Tíbias sem carenas. Metatarsômero I desde subigual até pouco mais longo que os dois seguintes reunidos.

Discussão. Eryphus difere de Tacyba gen. nov.: antenômeros VIII-XI, nos dois sexos, longos, nas fêmeas não-intumescidos; protórax mais largo do que longo, com os lados regularmente arredondados; élitros aplanados no dorso, com lados paralelos e pouco convexos junto aos ápices; pernas proporcionalmente curtas; clavas dos metafêmures cilíndricas; metatíbias cilíndricas e apenas mais curtas que os metafêmures. Em Tacyba: antenômeros VIII-XI, nos dois sexos, encurtados e nas fêmeas intumescidos; protórax tão longo quanto largo, sub-hexagonal; élitros convexos no dorso, adelgaçados no meio e abaulados no ápice; pernas proporcionalmente longas e robustas; metafêmures fusiformes; metatíbias achatadas e pouco mais longas que os metafêmures.

\section{Chave para espécies de Eryphus}

1. Cada élitro com uma carena do lado interno do úmero até o quinto apical; (pronoto pontuado-reticulado; élitros pretos, com faixa amarelada lateral). (Fig. 1) Brasil (Rio de Janeiro, São Paulo)

E. carinatus (Zajciw, 1970)

Élitros sem carenas

2

2(1). Élitros pretos com uma faixa amarelada transversal antes do meio; pronoto e terço basal dos élitros densamente pontuado-reticulados. (Fig. 2). Chile (Santiago, Valparaiso, Huaquen) ..

E. transversalis (Fairmaire \& Germain, 1864)

Élitros sem faixa transversal amarelada; pronoto sem pontos ou com pontos esparsos; élitros com pontos seriados

.. 3

3(2). Élitros bicolores, amarelados com faixas pretas ou pretos com faixas amarelas . 4

Élitros unicolores, pretos, preto-azulados ou azulmetálicos 6

4(3). Élitros pretos com estreita faixa amarelada látero-dorsal do úmero ao terço apical; antenas com reflexo azulado-metálico; antenômeros esparsamente pontuados e subglabros, os V-X distintamente serreados, mais evidente os V-VII; fronte subquadrada; lobos oculares inferiores moderadamente proeminentes (Fig. 3). Brasil (São Paulo) ............................ E. marginatus (Zajciw, 1970)

Élitros amarelos, com faixa sutural e ápices enegrecidos ou com as margens sutural e externa enegrecidas; antenas (fêmeas) sem brilho metálico; escapo e antenômeros III-IV pontuados e pubescentes; VVII, no máximo, discretamente expandidos no ápice externo; fronte transversa, lobos oculares inferiores bem proeminentes 5

5(4). Élitros com larga faixa escurecida ao longo da sutura que se expande distalmente e envolve toda a região apical; antenômeros II-XI pretos; pronoto alaranjado, usualmente com uma faixa negra a cada lado, mas às vezes unicolor. (Fig. 4). Argentina (Tucumán) E. bivittatus (Melzer, 1934)

Élitros estreitamente marginados de castanho-escuro ao longo da sutura, sobre a epipleura, na margem anterior e nos ápices; antenômeros II-XI amarelados; pronoto amarelo com 4 a 5 manchas arredondadas, castanhas ou pretas. (Fig. 5). Uruguai (Artigas, 
Tacuarembó) E. tacuarembo sp. nov.

6(3). Meso- e metafêmures com pontuação grossa e densa ..7 Meso- e metafêmures com pontos finos, rasos e esparsos

7(6). Ápices elitrais com espinho externo bem desenvolvido; proepimero inteiramente preto; face ventral, antenas e pernas com evidente reflexo azul-metálico. (Fig. 6). Brasil (Minas Gerais, Bahia ao Rio Grande do Sul), Paraguai e Argentina (Misiones)

E. bipunctatus Perty, 1832

Ápices elitrais desarmados ou com espinho lateral diminuto; proepimero enegrecido apenas junto às procoxas; face ventral, antenas e pernas pretas .... 8

8(7). Metasterno e urosternito I com pontos grossos e densos em toda superfície; face ventral com pilosidade longa e pouco adensada; meso- e metafêmures com pontos grossos, profundos e contíguos; antenas do macho ultrapassam o ápice elitral em dois artículos. (Fig. 7). Brasil (Rio de Janeiro)

E. carioca sp. nov.

Metasterno com pontos finos e rasos; urosternito I microcorrugado; face ventral com pilosidade longa, muito densa, deitada, quase oblitera o tegumento dos urosternitos; fêmures com pontos pouco marcados, irregularmente densos; antenas dos machos alcançam o ápice elitral. (Fig. 8). Brasil (Goiás, Paraná, Rio Grande do Sul), Argentina (Misiones) E. picticollis (Gounelle, 1911)

9(6). Extremidades elitrais usualmente com espinho desenvolvido no lado externo; comprimento do élitros $(4,7-6,0 \mathrm{~mm})$ igual a 2,47-2,75 vezes a largura umeral; pronoto, quando vermelho, geralmente com manchas pretas junto à orla basal. (Fig. 9). Argentina (Neuquen, Rio Negro, Chubut), Chile (Aconcagua, Cauquenes, Coquimbo, Choapa, Caulim, Fray Jorge, Linares, Malleco, Petorca, Santiago, Talca, Valdívia, Valparaiso) ........................ E. laetus (Blanchard, 1851)

Extremidades elitrais desarmadas ou com espinhos muito curtos; comprimento dos élitros $(4,0-5,2 \mathrm{~mm})$ igual a 2,9-3,1 vezes a largura umeral; pronoto sem manchas escuras. (Fig. 10). Brasil (São Paulo a Rio Grande do Sul), Uruguai E. flavicollis (Fisher, 1938)

\section{Eryphus tacuarembo sp. nov.} (Fig. 5)

Fêmea. Tegumento amarelo-alaranjado. Pronoto com 5 manchas arredondadas, castanho-escuras: duas láteroanteriores, duas látero-posteriores (mais afastadas entre si que as anteriores) e uma centro-basal, entre as posteriores. Élitros estreitamente marginados de castanho-escuro na base, contornando o escutelo, ao longo da sutura e, aos lados, dos úmeros aos ápices onde se une à faixa sutural; epipeluras concolores com o dorso. Fêmures, em alguns exemplares, com as clavas escurecidas. Mesosterno, metasterno e urosternitos acastanhados em extensão variável.

Fronte fortemente transversa, densamente pontuadorugosa, revestida por densa pubescência amarelada, decumbente. Sutura fronto-clipeal indistinta. Tubérculos anteníferos ligeiramente elevados, arredondados no topo. Lobos oculares inferiores proeminentes, os omatídios individualizados. Vértice opaco, pontuado-rugoso, aspecto áspero. Antenas, no máximo, alcançam o início do terço apical dos élitros. Escapo um pouco engrossado para o ápice, mais longo que o antenômero III; este tão longo quanto o IV e cerca de $1 / 4$ mais curto que o V; VI-X mais curtos, com comprimentos decrescentes e serreados; XI pouco mais longo que o X. Escapo e antenômeros II-V finamente pontuados e pubescentes, com cerdas alongadas na face inferior; VI-XI revestidos por pubescência curta.

Protórax tão largo quanto longo, com lados subparalelos. Pronoto pouco convexo. Tegumento opaco, sem pontos, o prosterno brilhante. Pronoto e lados do protórax com cerdas esparsas, longas e eretas, a superfície com micropubescência sedosa visível conforme a incidência da luz. Prosterno com cerdas eretas, curtas e esparsas. Mesosterno, metasterno e urosternitos com pontuação fina e superficial, densa a corrugada, mais evidente nos urosternitos; pilosidade brancosedosa, longa e decumbente, moderadamente densa, mais evidente no metasterno e nos lados dos urosternitos; cerdas longas e esparsas entremeadas. Escutelo subglabro.

Élitros com tegumento pouco endurecido e com pontos grossos, no dorso alinhados em quatro fileiras; pilosidade amarelada, muito longa e ereta. Ápices ligeiramente entalhados, as margens apicais serrilhadas. Urosternito V com lados convergentes e ápice arredondado

Fêmures com clavas delgadas; a pontuação fina e superficial; pilosidade esbranquiçada abundante, longa e ereta; pubescência esparsa. Ápice dos metafêmures atingem o ápice do urosternito III. Metatarsômero I quase tão longo quanto os dois seguintes somados; lobos laterais do metatarsômero III estreitos.

Dimensões, mm, fêmea. Comprimento total, 4,2-5,7; comprimento do protórax, 0,8-1,2; largura do protórax, 0,9-1,2; comprimento do élitro, 3,0-4,2; largura umeral, 1,2-1.5.

Material-tipo. Holótipo fêmea do URUGUAI, Tacuarembó, Puntas del Arroyo Laureles (Vassoura), 26.XI.1959, P. San Martín leg. (MNRJ). Parátipos: URUGUAI. Artigas: Sepulturas (Picada del Negro Muerto, Rio Cuareim), 2 fêmeas, 10.XII.1966, C.S. Carbonell, M. A. Monné \& P. R. San Martín leg. (MNRJ). Tacuarembó: Puntas del Arroyo Laureles (Vassoura), 4 fêmeas, 26.XI.1959, P. San Martín leg. (2 MZSP, 2 DZUP); 1 fêmea, 15.XII.1965, C.S. Carbonell, P.R. San Martín \& M. A. Monné leg. (MNRJ)

Discussão. Entre as espécies de Eryphus, E. tacuarembo sp. nov. e E. bivittatus (Melzer, 1934) são as que apresentam a fronte mais transversa, artículos apicais dos palpos mais dilatados e lobos oculares inferiores muito proeminentes, sendo 

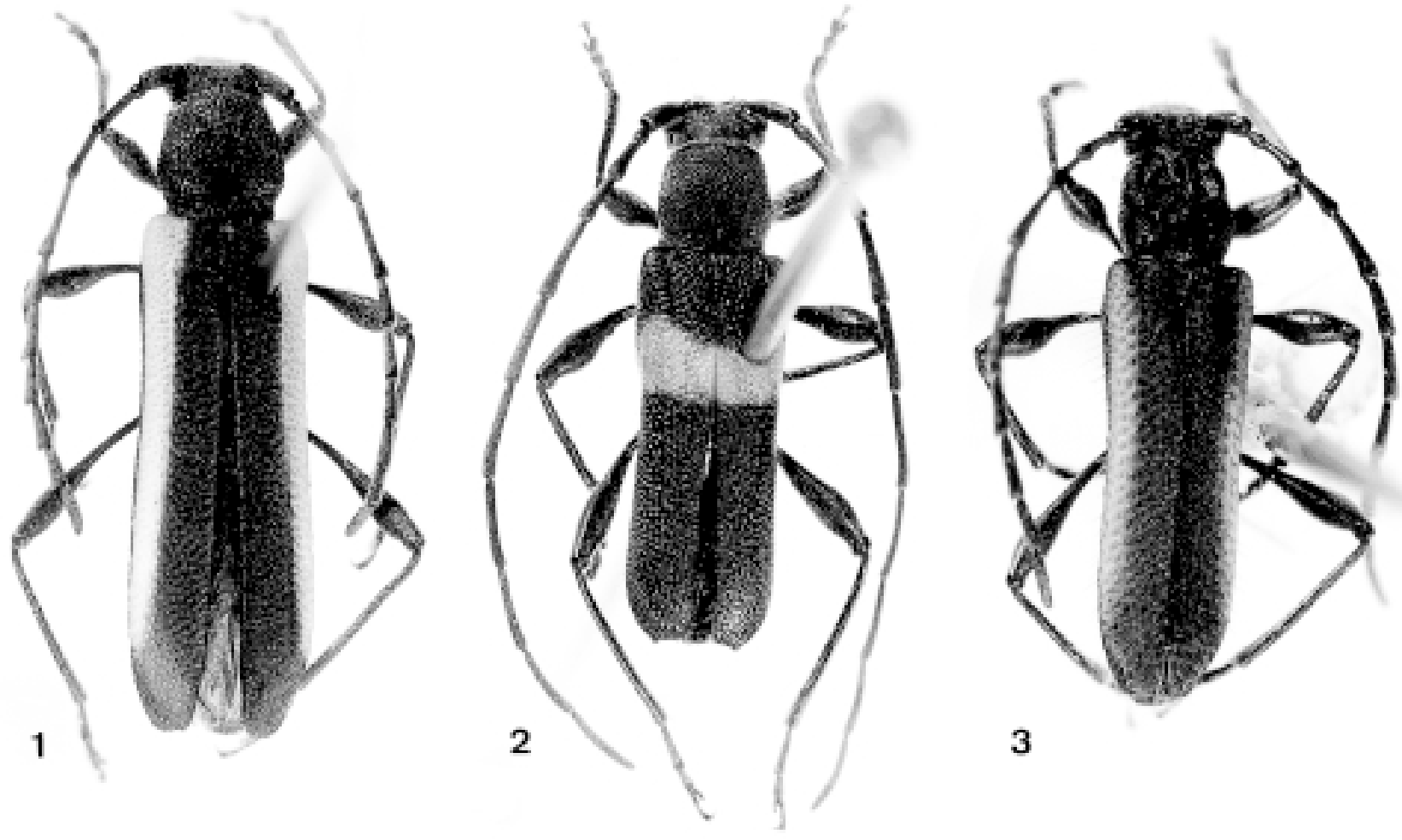

3

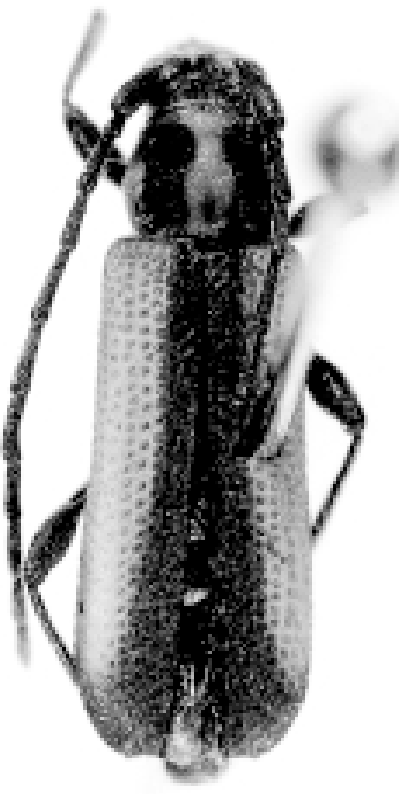

4

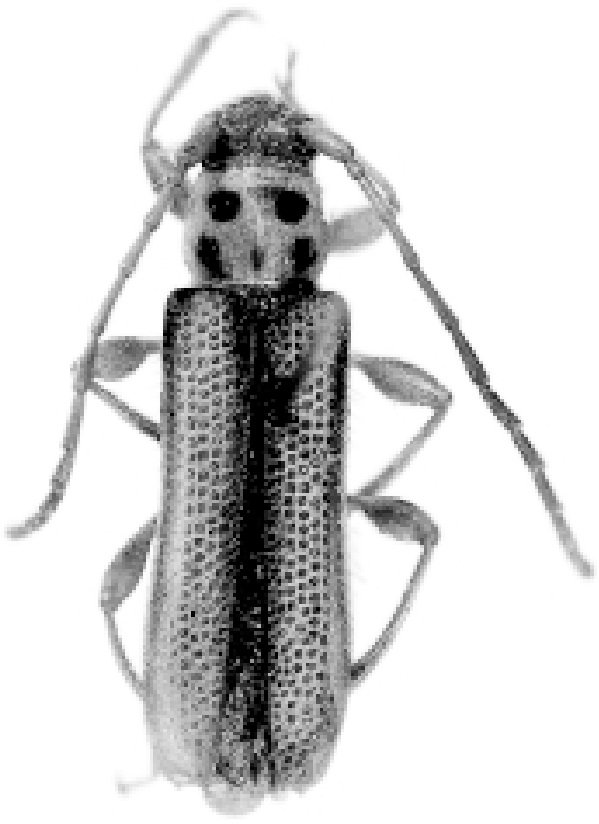

5

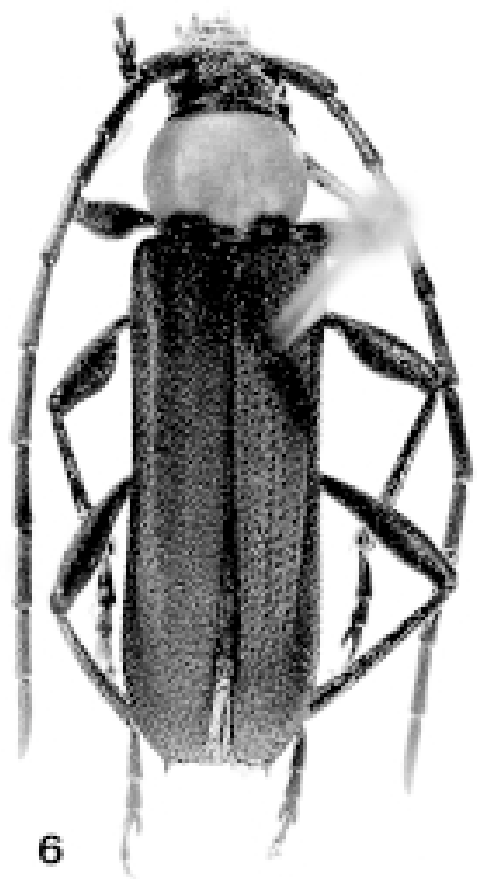

Figs. 1-6. 1, Eryphus carinatus, fêmea, Brasil, Rio de Janeiro: Rio de Janeiro (Corcovado), comprimento, 5,9 mm; 2, E. transversalis, macho, Chile, Valparaiso: Co. La Campana, comprimento, 8,2 mm; 3, E. marginatus, macho, Brasil, São Paulo: Serra da Bocaina, comprimento, 5,2 mm; 4, E. bivittatus, fêmea, Argentina, Tucumán, comprimento, 5,3 mm; 5, E. tacuarembo sp. nov., holótipo fêmea, comprimento, 5,0 mm; 6, E. bipunctatus, macho, Brasil, Paraná: Morretes, comprimento, 8,6 mm. 
bastante semelhantes pelo colorido geral do corpo (Figs. 4, 5). E. tacuarembo distingue-se de E. bivittatus, além dos caracteres mencionados na chave, também pela forma do protórax, com lados subparalelos e pouco convexo no dorso na primeira, e bem arredondado aos lados e convexo no dorso em $E$. bivittatus.

Variabilidade. Num dos parátipos de Puntas del Arroyo Laureles o dorso da cabeça é enegrecido, mas a fronte é amarelada. A mancha central escura do pronoto pode ser evanescente.

\section{Eryphus carioca sp. nov.}

(Fig. 7)

Macho. Cabeça, antenas e escutelo, pretos; protórax alaranjado com proepimeros enegrecidos junto às procoxas; élitros pretos, em alguns exemplares com discreto reflexo azulmetálico; pernas e face ventral (exceto prosterno) pretos.

Fronte pouco mais larga que longa, fina e densamente pontuado-rugosa, revestida por densa pubescência brancosedosa. Sutura fronto-clipeal indistinta. Vértice opaco e áspero. Antenas ultrapassam o ápice elitral em quase dois artículos no macho; na fêmea, alcançam o terço apical dos élitros. Antenômeros III-X com comprimentos subiguais, o $\mathrm{V}$ pouco mais longo, os VI-X um pouco projetados no ápice externo, o $\mathrm{XI}$ pouco mais longo que o X; na fêmea os VI-X mais curtos e decrescentes. Escapo e antenômeros II-V finamente pontuados e pubescentes com cerdas esbranquiçadas, longas, na face inferior; VI-XI densamente pubescentes.

Protórax mais largo que longo, arredondado aos lados, convexo no dorso. Pronoto e lados do protórax opacos, sem pontos, com cerdas esbranquiçadas, esparsas, longas e eretas, a superfície com micropubescência sedosa, visível sob incidência da luz. Prosterno menos opaco, sem pontos, com raras cerdas eretas, mais curtas que as do pronoto; processo prosternal com densa pubescência esbranquiçada. Mesosterno deprimido no disco, densamente pontuado-corrugado, revestido por densa pilosidade longa e deitada. Processo mesosternal elevado, tão largo quanto uma mesocoxa. Metasterno com pontos grossos, profundos, subcontíguos em toda a superfície; no disco com aspecto reticulado e microsesculturado, os interstícios lisos. Metasterno e urosternitos com pilosidade longa, ereta e pouco densa. Urosternito I, no disco e no processo intercoxal com pontuação semelhante à do metasterno, os pontos até maiores; aos lados com pontos finos e corrugados. Urosternitos II-V com escultura progressivamente mais fina e superficial, os IV-V brilhantes no disco. Urosternito $\mathrm{V}$ nos dois sexos com ápice arredondado. Escutelo quadrangular, glabro, entalhando no ápice.

Élitros opacos, com pontos profundos e subseriados; pêlos esbranquiçados, longos e esparsos. Ápices elitrais arredondados a subtruncados, inermes, as margens ligeiramente serrilhadas. Urosternito nos dois sexos com ápice arredondado.

Fêmures com pontuação grossa e profunda; os pontos contíguos, mais evidentes nos mesofêmures; com abundante pilosidade esbranquiçada, muito longa e ereta. Ápices dos metafêmures não alcançam ápice elitral. Metatarsômero I mais longo que II+III.

Dimensões, mm, macho/fêmea. Comprimento total, 6,0-7,7/ 7,5-8,2; comprimento do protórax, 1,2-1,6/1,6-1,8; largura do protórax, 1,3-1,8/1,8-2,0; comprimento do élitro, 4,5-5,5/5,7-6,0; largura umeral, 1,6-2,0/2,0-2,3.

Material-tipo. Holótipo macho do BRASIL, Rio de Janeiro: Rio de Janeiro (Corcovado), 10.XI.1958, Alvarenga \& Seabra col. (MNRJ). Parátipos, mesma procedência do holótipo: 1 fêmea, XII.1957, Seabra \& Alvarenga (MNRJ); 2 fêmeas, 10.X.1958, Alvarenga \& Seabra (MNRJ); 1 macho, 14.X.1959, Alvarenga \& Seabra (DZUP); 1 macho, X.1962, Alvarenga \& Seabra col. (MNRJ); 1 macho, 1 fêmea, 27.X.1975, M. A. Monné \& C. A. C. Seabra (MZSP), 3 fêmeas, 8.XI.1975, M. A. Monné \& C. A. C. Seabra col. (MNRJ), 1 macho, 15.X.1976, M. A. Monné (MNRJ), 1 fêmea, 18.X.1976, M. A. Monné \& C. A. C. Seabra (DZUP).

\section{Eryphus bipunctatus Perty, 1832}

(Fig. 6)

Eryphus bipunctatus Perty, 1832: 91, pr. 18, fig. 10.

Callideriphus bipunctatus; White, 1855: 296; Monné, 1994: 38 (cat.). Callideriphus atricollis Melzer, 1931: 56, pr. 11, fig. 7; Monné, 1994: 38 (cat.). Syn. nov.

Melzer (1931: 57) ao descrever Callideriphus atricollis chamou atenção para: "Pela formação geral, ponteação etc., esta espécie se parece muito com $C$. bipunctatus Perty, constituindo talvez sómente uma aberração desta, não obstante a coloração uniforme, preta do protórax." Não encontramos caracteres morfológicos para separar $C$. atricollis de $E$. bipunctatus e, embora em pequeno número, examinamos exemplares com o protórax bicolor o que confirma a sinonímia proposta.

Procedências do material examinado. BRASIL. Bahia: Condeúba. Espirito Santo: Baixo Guandu, Itapina. Minas Gerais: Caldas, Catas Altas (Serra do Caraça), Mar de Espanha, Passa Quatro, Pouso Alegre. Rio de Janeiro: Nova Friburgo, Teresópolis, Vassouras. São Paulo: Amparo, Barueri, Cotia, Eldorado, Itu (Fazenda Pau d'Alho), Mogi das Cruzes, Poá, São Paulo (Aclimação, Cocaia, Ipiranga, Morumbi). Paraná: Caiobá, Clevelândia, Curitiba, Guarapuava, Morretes, Piraquara, Ponta Grossa, Prudentópolis, Rolândia, Rio Negro. Santa Catarina: Mafra, Rio Vermelho, Seara (Nova Teutônia). Rio Grande do Sul: Pelotas, Porto Alegre. ARGENTINA. Misiones: Campo Grande.

\section{Eryphus bivittatus (Melzer, 1934) comb. nov.} (Fig. 4)

Callideriphus bivittatus Melzer, 1934: 77, pr. 1, fig. 3; Monné, 1994: 38 (cat.).

Restringimos nosso conceito de E. bivittatus aos exemplares que têm padrão de colorido semelhante ao do "cótipo" da ex-coleção Melzer (hoje incorporada ao MZSP) e que correspondem, razoavelmente, à descrição original. Esta espécie varia consideravelmente e não podemos afirmar que os exemplares examinados por BosQ (1951: 103) sejam, ou não, co-específicos com o "typo" (holótipo, no MACN). 

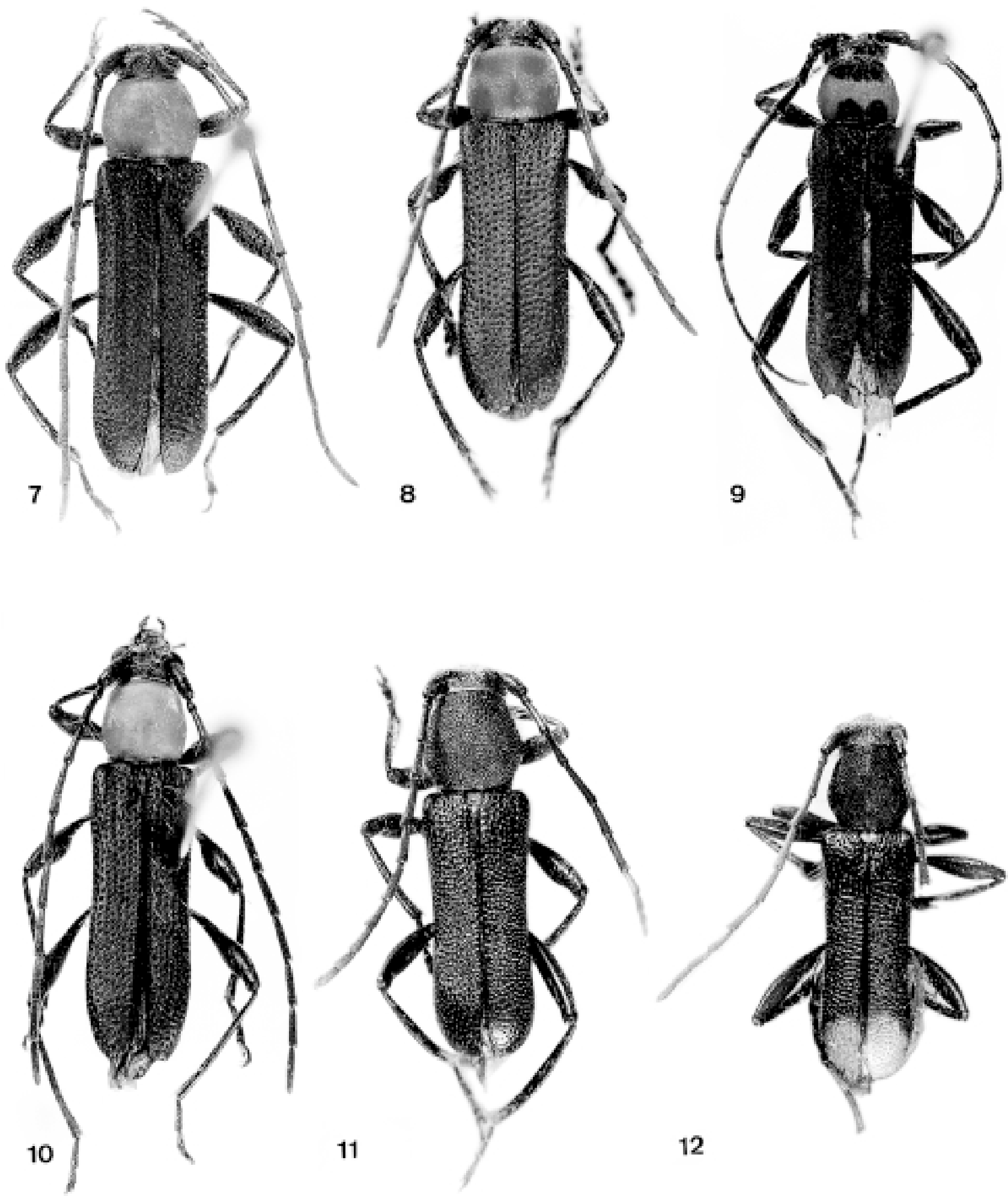

12

Figs. 7-12. 7, E. carioca sp. nov., holótipo macho, comprimento, $8,0 \mathrm{~mm} ; \mathbf{8}$, E. picticollis, síntipo macho, comprimento, 5,7 mm; 9, E. laetus, macho, Argentina, Neuquen, comprimento, $7,5 \mathrm{~mm}$; 10, E. flavicollis, macho, Brasil, Santa Catarina, Seara (Nova Teutônia) comprimento, 6,5 mm; 11, Tacyba tenuis, fêmea, Chile, Santiago: El Canelo, comprimento, 5,2 mm; 12, T. maculatus, macho, Chile, Santiago, comprimento, 4,5 mm. 
Material examinado. ARGENTINA. Tucumán: 2 fêmeas, III.1930, Girard col. (IMLA); El Siambón, 1 fêmea, 8.XI.1965, Terán col. (IMLA); Quebrada de Lules, 1 fêmea, XII.1928, [sem nome do coletor] (IMLA); Villa Nogues, 1 fêmea, "cótipo" (= parátipo), XII.1928, [R. Scheiter col., segundo Bosq (l. c.)] (MZSP).

\section{Eryphus carinatus (ZAJCIW, 1970) comb. nov.} (Fig. 1)

Callideriphus carinatus Zajciw, 1970: 265; Monné, 1994: 38 (cat.).

Originalmente descrita do Brasil, Rio de Janeiro, Rio de Janeiro (Corcovado) com base em único macho. Examinamos duas fêmeas procedentes da localidade-tipo, coligidas em 25.X.1957 e 10.X.1958 e outros dois exemplares de São Paulo (São João do Barreiro, Serra da Bocaina, 1600 m e 1650 m) que diferem do holótipo e das fêmeas do Corcovado pelo padrão do colorido elitral. Nestes exemplares, a mancha amarelada lateral dos élitros é mais larga na base, quase atinge o escutelo, depois estreita-se obliquamente e segue numa faixa estreita, lateral, até o nível do terço posterior. Nos indivíduos do Corcovado, a faixa amarelada não se aproxima do escutelo e tem largura constante da base até o sexto apical.

Eryphus carinatus tem colorido geral do corpo semelhante ao de E. marginatus Zajciw, 1970 (Fig. 3), mas difere consideravelmente desta e das demais espécies do gênero por apresentar evidente carena longitudinal nos élitros, do úmero ao quinto apical; antenas mais curtas que o corpo nos dois sexos; antenômeros III-V cilíndricos e do VI ao X nitidamente mais curtos que o $\mathrm{V}$ e serreados; corpo destituído de pêlos longos e esporões tibiais curtos. Além disso, o pronoto é densamente pontuado-reticulado, caráter que ocorre apenas em E. transversalis (Fig. 2).

\section{Eryphus flavicollis (Fisher, 1938) comb. nov. (Fig. 10)}

Callideriphus flavicollis Fisher, 1938: 135; Monné, 1994:39 (cat.).

FuCHS (1961) considerou duas formas: Callideriphus flavicollis m. quadripunctatus e C. flavicollis m. reductus. Estes dois nomes pertencem à categoria infrasubespecífica, portanto, não disponíveis segundo o Código Internacional de Nomenclatura Zoológica (ICZN 1999). Essas duas formas são aqui consideradas como variações intraespecíficas de $E$. picticollis (GounELLE 1911), tratadas mais à frente.

\section{Eryphus laetus (Blanchard, 1851) comb. nov.} (Fig. 9)

Callideriphus laetus Blanchard in Gay, 1851: 488, pr. 29, fig. 6; Monné, 1994: 39 (cat.)

\section{Eryphus marginatus (Zajciw, 1970) comb. nov.} (Fig. 3)

Callideriphus marginatus Zajciw, 1970: 266, fig. 2; Monné, 1994: 39 (cat.).
Além do holótipo fêmea, examinamos um macho também procedente da localidade-tipo, mas coletado por Seabra \& Oliveira em XI.1969. Neste macho, as antenas ultrapassam os ápices elitrais em um artículo, os antenômeros VI-X são mais longos do que nas fêmeas e pouco expandidos no lado externo da extremidade.

\section{Eryphus picticollis (Gounelle, 1911) comb. nov.} (Figs. 8, 13)

Callideriphus picticollis Gounelle, 1911: 216; Monné, 1994: 40 (cat.).

Variabilidade. E. picticollis parece estar sujeita à variabilidade na cor do pronoto e dos élitros. Essas variações correspondem aos padrões de distribuição 1-3 indicados na Fig. 13; o padrão 4 poderá, ou não, pertencer a E. picticollis.

Nos exemplares da forma típica (Fig. 13, padrão 1), procedentes do sul de Goiás, o pronoto é amarelado ou tem quatro manchas, indistintas, avermelhadas: duas anteriores e duas basais; os élitros são azuis-metálicos (Fig. 8).

Material examinado. BRASIL, Goiás: Jataí, 2 machos e 10 fêmeas, 12.1897-I.1898 C. Pujol, síntipos (MNHN); 1 macho, idem (MZSP); 3 fêmeas, MZSP 14747 (MZSP).

Outra população (Fig. 13, padrão 2) ocorre no leste do Paraná, no oeste de Santa Catarina e em Misiones (Argentina) e consiste de exemplares com pronoto habitualmente amarelo, mas também amarelado com manchas alaranjadas ou acastanhadas (duas na base e duas anteriores ou apenas duas anterioes). Os élitros são azuis-metálicos, mas num exemplar são pretos, sem brilho metálico. A esta população corresponde Callideriphus flavicollis m. reductus Fuchs, 1961.

Material examinado. BRASIL, Paraná: Castro (Carambeí), 1 macho, 2 fêmeas, 21.XI.1970, Moure \& Marinoni col.; 2 fêmeas, VI.1971, Marinoni col.; 4 machos, 7 fêmeas, XII.1971, Napp col. (DZUP); Curitiba, 1 fêmea, XII.1934 (MZSP); Rolândia, 1 macho, A. Maller col. (MZSP) ARGENTINA, Misiones: Concepción de la Sierra (Santa Maria), 1 fêmea, X.1945, Viana col. (MNRJ).

Uma outra população (Fig. 13, padrão 3) ocorre nas cidades próximas a Porto Alegre, Rio Grande do Sul, onde o pronoto é amarelado com manchas castanhas evidentes, duas anteriores e duas posteriores; élitros pretos com reflexo azulado metálico. Esta população corresponde a Callideriphus flavicollis $\mathrm{m}$. quadripunctatus Fuchs, 1961, descrita de Porto Alegre.

Material examinado. BRASIL, Rio Grande do Sul: Estrela, 1 fêmea, 22.X.1998, L. Moura col.; Porto Alegre (Jardim Botânico), 1 macho, IX.1998, L. Moura col.; Viamão, 1 fêmea, X.1997, L. Moura col. (MCNZ). Um parátipo fêmea de Callideriphus flavicollis m. quadripunctatus (MAGD), procedente de Porto Alegre, foi estudado por meio de diapositivo.

Reconhecemos ainda uma população (Fig. 13, padrão 4) no sul do Rio Grande do Sul, Brasil e em Entre Rios, Argentina, onde o pronoto é amarelado com quatro manchas castanhas 


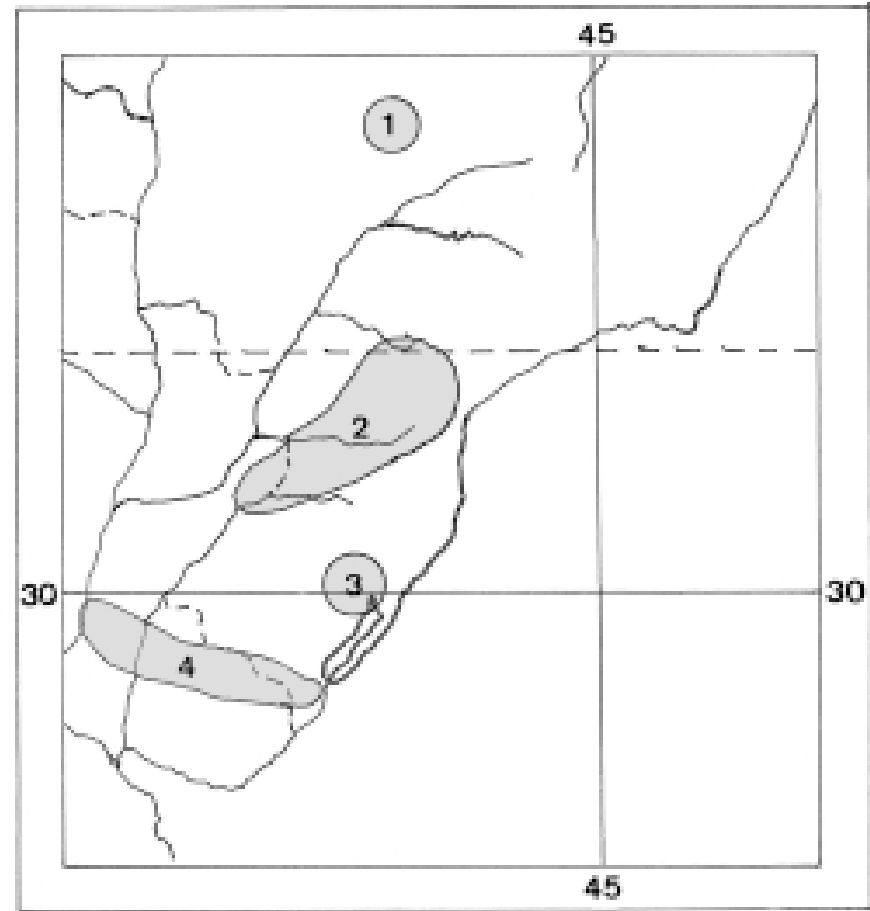

Fig. 13. Distribuição geográfica de Eryphus picticollis. 1, forma típica; 2, formas com pronoto unicolor ou com duas a quatro manchas alaranjadas ou acastanhadas e élitros azuis-metálicos; $\mathbf{3}$, formas com pronoto com 4 manchas castanhas evidentes e élitros pretos com reflexo azuladometálico; $\mathbf{4}$, formas com pronoto com quatro manchas castanhas, élitros pretos com epipleuras amareladas e pernas bicolores.

bem marcadas, élitros pretos com epipleuras amareladas na base e pernas bicolores, pretas na clava e pedúnculo amareloavermelhado. Esta forma poderá pertencer à espécie próxima de E. picticollis, mas o material disponível é insuficiente para conclusões.

Material examinado. BRASIL, Rio Grande do Sul: Rio Grande (Reserva Ecológica do Taim), 1 fêmea, X.1985, C.J. Becker col. (MCNZ). ARGENTINA, Entre Rios: 1 macho, XI.1942, Rosillo leg. (MNRJ); Pronunciamiento (Rio Gualeguaychú), 1 macho, 2 fêmeas, XI.1975 (MZSP).

Eryphus transversalis (Fairmaire \& Germain, 1864) comb. nov. (Fig. 2)

Callideriphus transversalis Fairmaire \& Germain, 1864: 389; Monné, 1994: 40 (cat.).

FAIRMAiRe \& Germain (1864: 389) descreveram a faixa transversal amarelada dos élitros como central e os ápices elitrais como inermes. Examinamos um síntipo da Coleção Fairmaire (MNHN) e verificamos que a faixa amarelada localizase à frente do meio e que os ápices elitrais apresentam curta projeção no lado externo. Este último caráter apresenta alguma variabilidade. Nos exemplares examinados, os ápices elitrais podem ter apenas uma curta projeção externa, ou são entalhados com projeções curtas, externa e sutural.
Eryphus transversalis, até o momento, tem distribuição restrita ao Chile. Distingue-se prontamente das demais espécies do gênero por ser a única que apresenta faixa amarela transversal nos élitros e pronoto e base dos élitros densamente pontuado-reticulados.

Material examinado. CHILE: síntipo macho (MNHN), 1 macho, 1944, H. Zellibor, 3 machos, 2 fêmeas (MNRJ); Maule: 1 fêmea, XI.1993, Peña \& Ugarte leg. (MNNC). Santiago: 1 fêmea, Kuschel leg. (MNRJ); Co. (?) Manquehue, 3 machos, XII.1973, G. Arriagada, 1 fêmea, 19.X.1974, M. Donoso (MNNC); Curico, 1 fêmea, X.1939, H. Zellibor leg. (MNRJ); El Canelo, 1 macho, 10.XI.1946, H. Zellibor leg. (MNRJ), 1 fêmea, X.1949, 1 macho, XI. 1949, Gutierrez col. (MNRJ); Pirque, 1 fêmea XI.1981, R. Perez de Arce (MNNC). Huaquén: Co. Iman, 1 fêmea, XII.1981, Solervicens col. (MNNC). Valparaiso: Co. La Campana, 1 macho, XII.1979, C. Vivar col., 1 macho, XII.1978, Solervicens col. (MNNC).

\section{Tacyba gen. nov.}

Espécie-tipo: Callideriphus maculatus Cerda, 1988.

Etimologia. Tupi, tacyba = formiga, alusivo à forma do corpo .

Pequenas dimensões (comprimento, 5,4-6,0 mm). Corpo com longos pêlos esbranquiçados e eretos, mais abundantes no pronoto. Fronte curta, transversa, plana e oblíqua. Sutura fronto-clipeal indistinta. Tubérculos anteníferos discretamente elevados, arredondados no topo. Região posterior da cabeça, atrás dos lobos oculares superiores, abaulada. Genas reduzidas, com com cerca de um quarto do diâmetro dos lobos oculares inferiores. Olhos finamente facetados, emarginados; lobos oculares inferiores desenvolvidos, proeminentes, ocupam quase toda a região lateral da cabeça; lobos superiores estreitos, com cerca de um quarto da largura dos inferiores, tão distantes entre si quanto o quíntuplo da largura de um lobo. Mandíbulas delgadas, arredondadas na face lateral externa, aguçadas no ápice. Artículos apicais dos palpos maxilares e labiais securiformes, tão longos quanto os dois anteriores somados.

Antenas com 11 artículos, desarmadas e sem sulcos ou carenas. Nos machos alcançam, ou quase, o ápice elitral; nas fêmeas, atingem o terço apical dos élitros. Escapo cilíndrico, pouco mais curto que o antenômero III; III e IV cilíndricos, o III pouco mais longo; V a VII um pouco expandidos no ápice externo; V e VII subiguais e pouco mais longos que o VI; VIII a XI serreados, nitidamente mais curtos que o VII; XI apendiculado, pouco mais longo que o $\mathrm{X}$. Nas fêmeas, antenômero V o mais longo; VI-XI decrescentes, mais evidentemente os antenômeros VIII-X que são curtos e um pouco intumescidos.

Protórax tão ou pouco mais longo que largo; lados subangulosos, com aspecto sub-hexagonal, ou arredondados ao nível do meio. Pronoto convexo. Prosterno sem pontuação sexual, quase sem pontos e com rugas transversais. Processo prosternal muito estreito entre as procoxas. Cavidades coxais anteriores arredondadas, discretamente angulosas aos lados e abertas atrás. Processo mesosternal plano, pouco mais estreito 
que uma mesocoxa, os lados ligeiramente convergentes para o ápice e sem superfícies articulares; ápice com entalhe mediano para encaixe do metasterno. Cavidades coxais intermediárias fechadas. Pro- e mesocoxas arredondadas, um pouco projetadas. Urosternitos transversos; urosternito V arredondado no ápice nos machos, truncado nas fêmeas. Ovipositor alongado, membranoso, estilos apicais.

Élitros proporcionalmente curtos e estreitos, comprimento cerca de 2,5 a 3 vezes a largura umeral; esta pouco maior que a maior largura do protórax. Convexos no dorso, um pouco adelgaçados ao nível do meio e abaulados para os ápices; extremidades arredondadas em conjunto.

Pernas robustas e alongadas. Fêmures anteriores e médios gradualmente clavados. Metafêmures alongados, fusiformes, um pouco achatados lateralmente; abas apicais arredondadas; nos machos, alcançam, ou quase, o ápice elitral; nas fêmeas, aproximam-se, mas não atingem as extremidades. Tíbias sem carenas. Metatíbias achatadas lateralmente, pouco mais longas que os metafêmures; esporões tibiais curtos. Metatarsômero I tão longo quanto os dois seguintes somados. Metatarsômero III com lobos estreitos, mas não-lineares.

Comentários. Tacyba inclui apenas duas espécies com distribuição restrita ao Chile e noroeste da Argentina: T. tenuis (Blanchard, 1851) e T. maculata (Cerda, 1988).

\section{Tacyba tenuis (Blanchard, 1851) comb. nov.} (Fig. 11)

Callideriphus tenuis Blanchard in Gay, 1851: 489; Cerda, 1986: 35 (cat.); Monné, 1994:40 (cat.).

Callideriphus testaceicornis Fairmaire \& Germain, 1859: 505. Syn. nov. Tillomorpha (Batyle) testaceicornis; Chevrolat, 1862: 526.

Tillomorpha testaceicornis; Lacordaire, 1869: 91; Cerda, 1986: 37 (cat., nomen dubium); Monné, 1993: 77.

Callideriphus clathratus Fairmaire \& Germain, 1860: 5; Cerda, 1986: 35 (cat.); Monné, 1994: 38 (cat.). Syn. nov.

Callideriphus niger Philippi \& Philippi, 1864: 383; Cerda, 1986: 35 (cat.); Monné, 1994: 40 (cat.). Syn. nov.

Callideriphus tenuis, C. testaceicornis, C. clathratus e $C$. niger foram descritas do Chile. Segundo as descrições originais, as diferenças entre as espécies estão restritas à coloração das antenas (fulvas com os ápices enegrecidos em C. tenuis, castanho-amareladas em C. testaceicornis e C. clathratus, e negras em $C$. niger) e à pontuação elitral mais densa em $C$. clathratus.

Os tipos não foram examinados, mas estudamos número razoável de exemplares provenientes do Chile, incluindo muitos exemplares da ex-coleção Peña (atualmente no MZSP) e da excoleção Bosq (atualmente no MNRJ) e verificamos que as diferenças mencionadas acima constituem variações intraespecíficas. Além disso, não detectamos outras diferenças morfológicas que permitissem distinguir as espécies, o que justifica as sinonímias propostas.

FAIRMAIRE \& GERMAIN (1859) descreveram Callideriphus testaceicornis do Chile, possivelmente com base num exemplar (foi dada apenas uma dimensão). Chevrolat (1862: 526) transferiu Callideriphus testaceicornis para Tillomorpha Blanchard, 1851 (Tillomorphini) sem apresentar justificativas e referiu-se claramente à espécie de Fairmaire \& Germain: "Callideriphus testaceicornis Fairm., An. 1859, p. 505, no $3=$ Clytus tantillus Dej." Exceto LACORDAIRE (1869), que tratou testaceicornis nos dois gêneros, Tillomorpha (p. 91) e Callideriphus (p. 132), os autores subseqüentes aceitaram Chevrolat (l.c.) e inseriram C. testaceicornis em Tillomorpha (Gemminger \& Harold 1872; Philippi 1887; Aurivillius 1912; MonNé, 1993). CERDA (1986: 37) considerou Tillomorpha testaceicornis um nomen dubium. Pelos caracteres mencionados, Chevrolat (1862), provavelmente, tratou de espécie distinta da de FAIRMAIRE \& GERMAin (1859) e por isso transferiu-a para Tillomorpha. Com base nas descrições originais e no material examinado não vemos argumentos ou justificativas para não interpretá-la como sinônima de Callideriphus tenuis Blanchard, 1851.

Tipos, localidade-tipo. Os tipos de Callideriphus tenuis Blanchard, C.testaceicornis Fairmaire \& Germain e C. clathratus Fairmaire \& Germain não foram localizados por um dos autores (DSN) no MNHN. BLANCHARD (1851) mencionou que C. tenuis é bastante comum “...em los árboles de Santa Rosa, Valparaiso, etc...”. FAIRMAIRE \& GERMAIN $(1859,1860)$ registraram apenas "Chili" como localidade-tipo de $C$. testaceicornis e $C$. clathratus. C. niger foi descrita de Aconcágua (PHILIPPI \& PhilipPi, 1864) e, de acordo com Horn \& KAHLe (1936), o material-tipo está depositado no MNNC.

Material examinado. CHILE. 2 machos, 3 fêmeas, ex-col. Porter, 1 macho (MNRJ); Aconcagua: Los Andes, 1 fêmea, XII.1982, R. Perez de Arce col. (MNNC); Río Blanco, 5 exs., XI.1958, 2 exs., XII.1958, Dirings (MZSP); 1 fêmea (1500 m), XI.1957, Hofmann leg. (MNNC). Valparaiso: Algorobo, 1 macho, X.1982, R. Perez de Arce col. (MNNC); Co. La Campana, 1 fêmea, XII.1979, Solervicens (MNNC); Salto, 1 macho, XI.1940 [sem nome do coletor] (MNRJ). Santiago: 1 fêmea (MNRJ); El Canelo, 1 fêmea, XI.1944 [sem nome do coletor], 1 macho (MNRJ); 3 fêmeas, XI.1948, Gutierrez col., 1 ex., X.1949, Gutierrez col. (MZSP); 1 macho, XI.1949, Gutierrez col., 1 fêmea, X.1950, 1 macho, 1 fêmea, X.1951 (MNRJ), 2 fêmeas, X.1952, 1 ex., XI.1952, 1 ex., X.1961, Cerda col. (MZSP); El Ingenio, 2 fêmeas, XII.1974 [sem nome do coletor] (MNRJ), 2 exs., idem (MZSP), 1 fêmea, XII.1974, M. Donoso (MNNC); El Manzano, 1 macho, X.1975, Arriagada col., 1 fêmea, XI.1980 (MZSP); El Monte, 1 fêmea, X.1944, Ramirez col. (MNRJ); Las Cruces (Cordillera Parral), 1 macho, 2 ex., XI.1960, M. Rivera col. (MNRJ); La Dormida, 1 fêmea, XI.1982, J. Escobar col. (MZSP); Maipo, 1 ex., XI.1980, Cerda col. (MZSP); Santiago, 1 ex., XI.1945, Gutierrez col. (MZSP); Malleco: Galletue, 1 fêmea, XI.1980, Peña col. (MZSP). Viña del Mar: 1 fêmea, X.1948 (MNRJ). Vilches: Talca, 1 macho, I.1986, R. Perez de Arce (MNNC). ARGENTINA. Chubut: Esquel, 1 ex., I.1941, Koehler col., ex-coleção Bosq (MNRJ). Rio Negro: Bariloche, 1 fêmea, I.1949, 1 fêmea (MNRJ).

\section{Tacyba maculata (Cerda, 1988) comb. nov.} (Fig. 12)

Callideriphus maculatus Cerda, 1988:69; Monné, 1994: 39 (cat.).

Material examinado. CHILE. Santiago: 2 machos, 3 fêmeas (MNRJ); 
Cerro Vizvachas (2000 m), 1 fêmea, XI.1981, L. Peña col. (Alótipo, MZSP); 3 machos, XI.1981, L. Peña col. (Parátipos, MZSP); 2 fêmeas, XI.1981, L. Peña col. (MNNC). Ñuble: Cerro El Roble (1700 m), 1 fêmea, XI.1992, Penã \& Ugarte col. (MNNC). Las Trancas: Cord. de Chillan, 1 ex. XII.1986, R. Perez de Arce (MNNC).

Agradecimentos. A M. A. Monné (MNRJ) e G. Tavakilian (MNHN) que possibilitaram o estudo de síntipos de Callideriphus transversalis Fairmaire \& Germain e também pela tentativa de localização dos tipos de Blanchard e de Fairmaire \& Germain no MNHN. A A. M. Sakakibara (DZUP) pelas fotos.

\section{REFERÊNCIAS}

Aurivillius, C. 1912. Coleopterorum Catalogus, pars 39, Cerambycidae: Cerambycinae. Berlin, W. Junk, 574 p.

Blanchard, C. E. 1851. Fauna Chilena, Insectos, Coleópteros. In Gay, C. Historia fisica y política de Chile. Zoologia 5: 285-563.

Bose, J. M. 1951. Novedades en Cerambícidos del Norte Argentino (Col., Cerambycidae. Revista de la Sociedad Entomologica Argentina 15(1-3): 96-107.

Cerda, M. 1986. Lista sistemática de los cerambícidos chilenos (Coleoptera: Cerambycidae). Revista Chilena de Entomología 14:29-39.

Cerda, M. 1988. Nuevo Cerambycinae de Chile (Coleoptera: Cerambycidae). Revista Chilena de Entomología 16: 69-70.

Chevrolat, A. 1862. Description de clytides américains. Annales de la Societé Entomologique de France (4) 2: 517-536.

Fairmaire, L. \& P. Germain. 1859. Révision des cóleoptères du Chile (suite). Annales de la Societé Entomologique de France (3) 7: 483-532.

Fairmaire, L. \& P. Germain. 1860. Coleoptera chilensia. Paris, 8 p.

Fairmaire, L. \& P. Germain. 1864. Révision des cóleoptères du Chile. Revue et Magasin de Zoologie 16: 258-394.

Fisher, W. S. 1938. New neotropical Cerambycidae. Revista de Entomologia 8(1-2): 135-153.

Fuchs, E. 1961. Neue cerambyciden aus südbrasilien. Pesquisas, Zoologia, 12: $5-10$.

Gemminger, M. \& E. Harold. 1872. Catalogus Coleopterorum hucusque descriptorum synonymicus et systematicus. Monachii, 9: 2699-2988.

GounelLe, E. 1911. Liste des cérambycides de la région de Jatahy, Etat de
Goyaz, Brésil. Annales de la Societé Entomologique de France 80: $103-252$.

Horn, W. \& I. Kahle. 1936. Über entomologische Sammlungen, Entomologen \& Entomo-Museologie. Entomologische Beihefte Berlin-Dahlem 3: 162-296.

Lacordaire, J. T. 1869. Histoire naturelle des insectes. Genera des Coléoptères. Paris, Librairie Encyclopedique de Roret, 9(1): 1409.

Iczn - International Comission Of Zoological Nomenclature. 1999. International Code of Zoological Nomenclature, $4^{\text {th }}$ Ed. London, The International Trust for Zoological Nomenclature, $\mathrm{xxix}+306 \mathrm{p}$

Melzer, J. 1931. Longicórneos americanos, principalmente do Brasil, novos ou pouco conhecidos (Coleoptera, Cerambycidae). Archivos do Instituto Biológico 4: 51-82.

Melzer, J. 1934. Novos subsídios para o conhecimento dos cerambycideos neotrópicos. Revista de Entomologia 4(1): 70-110.

Monné, M. A. 1993. Catalogue of the Cerambycidae (Coleoptera) of the Western Hemisphere. Part IX. São Paulo, Sociedade Brasileira de Entomologia, 131 p.

Monné, M. A. 1994. Catalogue of the Cerambycidae (Coleoptera) of the Western Hemisphere. Part X. São Paulo, Sociedade Brasileira de Entomologia, $81 \mathrm{p}$

NAPP, D. S. \& U. R. Martins. 1995. Revisão do gênero Chrysoprasis A.Serville, 1834 (Coleoptera, Cerambycidae, Cerambycinae, Heteropsini). I. Grupo basalis. Revista Brasileira de Entomologia 39(4): 901-910

Napp, D. S. \& U. R. Martins. 2002. Unabiara, um novo gênero de Heteropsini (Coleoptera, Cerambycidae). Revista Brasileira de Entomologia 46(1): 71-76

PerTy, J. A. M. 1832. De insectorum in America meridionali habitantiam vitae genera, moribus ac distributione geographica observationes nonnullae. In: Delectus animalium articulatorum ..., collegerunt Dr. J. B. de Spix et Dr. C. F. Ph. De Martius. Monachii, pp. 61-124.

Philippi, F. H. E. 1887. Catálogo de los Coleópteros de Chile. Anales de la Universidad de Chile 71: $619-806$.

Philippi, R. A. \& F. H. E. Philippi. 1864. Beschreibung einiger neuen Chilenischen Kafer. Stettiner Entomologische Zeitung 25: 266284; 313-406.

White, A. 1855. Catalogue of the coleopterous insects in the collection of the British Museum. Longicornia 2. London, 8 : 175-412.

Zajciw, D. 1970. Novos Longicórneos neotrópicos XVII (Col., Cerambycidae).Anais da Academia Brasileira de Ciências 42(2): 263-267. 